\title{
Weekly pegylated liposomal doxorubicin and paclitaxel in patients with metastatic breast carcinoma: A phase II study
}

\author{
VITA LEONARDI, VALENTINA PALMISANO, ALESSIO PEPE, ANTONELLA USSET, \\ GIOVANNA MANUGUERRA, GIUSEPPINA SAVIO, MANUELA TAMBURO DE BELLA, \\ AGATA LAUDANI, MASSIMO ALÙ, MARIA PIA CUSIMANO, \\ CATERINA SCIANNA, ARMANDO GIRESI and BIAGIO AGOSTARA
}

Division Of Medical Oncology, Oncologic Department, Arnas Civico, Palermo, Italy

Received February 23, 2010; Accepted May 13, 2010

DOI: 10.3892/ol_00000131

\begin{abstract}
Pegylated liposomal doxorubicin (PLD) has the advantage of delivering active anthracycline directly to the tumor site, while exposing the patient to a lesser degree of doxorubicin-associated toxicities. Recently, a regimen in which paclitaxel is infused weekly over $1 \mathrm{~h}$ produced substantial antitumor activity with little myelosuppression. We designed a phase II trial to study the efficacy and toxicity of $10 \mathrm{mg} / \mathrm{m}^{2}$ PLD on Days 1,8 and 15 , plus $70 \mathrm{mg} / \mathrm{m}^{2}$ paclitaxel weekly in patients with untreated metastatic breast cancer and a high risk of cardiotoxicity. The study included 35 patients, with 31 $(88.5 \%)$ evaluable for efficacy and $35(100 \%)$ for toxicity. A total of 28 patients $(80 \%)$ had two or more sites of disease. Overall, 4 complete and 16 partial responses were noted with an overall response rate of $64.5 \%$, with 6 cases of stable and 5 cases of progressive disease. Toxicity was found to be manageable in that the only grade 3-4 side effects recorded were palmar-plantar erythrodysesthesia, 8.5\%; mucositis, $2.8 \%$; leucopenia, $12.5 \%$; anemia, $2.8 \%$ and AST/ALT, $2.8 \%$. No cardiotoxicity was observed. In conclusion, weekly PLD plus paclitaxel appears to be a well-tolerated and effective approach for metastatic breast cancer patients with a high risk of cardiotoxicity.
\end{abstract}

\section{Introduction}

Anthracyclines demonstrate significant disease activity in breast cancer and are a key component of the therapy regimen in both early and advanced disease $(1,2)$. Despite its excellent antitumor activity, conventional doxorubicin has a relatively low therapeutic index and its use is limited due to the development of myelosuppression, alopecia, acute nausea and vomiting,

Correspondence to: Dr Vita Leonardi, Division of Medical Oncology, Oncologic Department, Arnas Civico, Piazza Nicola Leotta 2, 90127 Palermo, Italy

E-mail: vitaleonardi@yahoo.it

Key words: pegylated liposomal doxorubicin, paclitaxel, metastatic breast carcinoma, weekly chemotherapy, cardiotoxicity stomatitis and cumulative cardiotoxicity (3). Cardiotoxicity occurs more commonly and at lower cumulative doses than previously thought. In one retrospective analysis involving 630 doxorubicin-treated patients, cardiac events were observed in $7,9,18,38$ and $65 \%$ of patients at a cumulative doxorubicin dose of 150, 250, 350, 450 and $550 \mathrm{mg} / \mathrm{m}^{2}$, respectively (4). Several factors increase the risk of developing irreversible cardiotoxicity. These include the extent of anthracycline exposure, age (both the very young and elderly have greater risk), a history of cardiac disease, diabetes and previous cancer therapies, such as mediastinal radiotherapy (RT) and concurrent use of chemotherapy that includes paclitaxel or trastuzumab (5-8).

In these cases, pegylated liposomal doxorubicin (PLD) is an attractive option. PLD has demonstrated comparable efficacy to doxorubicin with a favorable toxicity profile. It is associated with less alopecia, myelotoxicity and cardiac toxicity than free doxorubicin, but with higher rates of palmarplantar erythrodysesthesia (PPE) and mucositis. At least two factors may contribute to the lower cardiotoxicity associated with PLD: i) changes in tissue distribution with less drug exposure to sensitive organs, such as the heart muscle, and ii) slow release of the drug, which may avoid high peak plasma concentrations (9).

Investigators have evaluated whether dose- and scheduledependent adverse events of PLD, such as stomatitis and PPE, are able to be minimized. Subsequently, an empiric dose reduction of PLD $40 \mathrm{mg} / \mathrm{m}^{2}$ every 4 weeks has been suggested (10). Moreover, the results of a phase I study in patients with advanced solid tumors indicate that alternative dosing regimens may improve the tolerability of PLD (11). One retrospective analysis was performed to test the hypothesis that toxicities decrease when lower doses of PLD at less frequent intervals are administered (12).

Combination therapy with PLD is potentially attractive because of its non-overlapping toxicity profile with other agents commonly used in these settings, such as gemcitabine $(13,14)$, vinorelbine $(15,16)$, cyclophosphamide $(17,18)$, paclitaxel (19-22) and docetaxel (23-26). Response rates range between 31 and $75 \%$, with a low incidence of symptomatic cardiac events.

Paclitaxel is one of the most established and active anticancer drugs (27). Phase II studies of paclitaxel showed significant antitumor activity in various types of solid tumors, 
including ovarian, non-small cell lung and head and neck. In previously treated patients with metastatic breast carcinoma (MBC), paclitaxel produced objective responses in 30-60\% of the cases (28).

Investigators have examined 'dose-dense' chemotherapy, with drugs being administered more frequently, such as once a week or every 2 weeks (29-32). The administration of taxanes on a weekly schedule, while maintaining the dose intensity of a 21-day schedule, showed a marked reduction in grade 3-4 leukopenia and increased activity in terms of response rate and time-to-progression.

These results showed that there is a rational basis for the use of weekly PLD and paclitaxel as front-line therapy in patients with MBC at high risk of cardiotoxicity.

\section{Patients and methods}

Patient eligibility. Female patients with histologically confirmed $\mathrm{MBC}$ and with a high risk of cardiotoxicity (previous adjuvant doxorubicin-based chemotherapy or previous RT to mediastinal and/or left chest wall and/or hypertension) were eligible. Patients who had received prior adjuvant anthracyclines were considered eligible if the relapse occurred 12 months after conclusion of the adjuvant chemotherapy. An Eastern Cooperative Oncology Group (ECOG) performance status of $0-2$, age $>65$ ( $<65$ if high risk of cardiotoxicity), life expectancy $>3$ months, no concurrent uncontrolled medical illness, no other malignancies (with the exception of squamous cell carcinoma of the skin treated by surgery), baseline left ventricular ejection fraction (LVEF) $>50 \%$ and sufficient hepatic and bone marrow function were also required. Patients were excluded if they had cardiac diseases, including congestive heart failure, atrial or ventricular arrhythmia, were pregnant or breast-feeding. Participants provided written informed consent prior to enrollment, and the study protocol was approved by the institutional ethics committees.

Chemotherapy. PLD $10 \mathrm{mg} / \mathrm{m}^{2}$ in $250 \mathrm{ml}$ of $5 \%$ glucose solution was administered as a 30-min infusion on Days 1, 8 and 15 every 4 weeks.

Paclitaxel in $250 \mathrm{ml}$ of normal saline was administered as a 1 -h infusion weekly at a dose of $70 \mathrm{mg} / \mathrm{m}^{2}$. The patients were pre-medicated with dexamethasone $(4 \mathrm{mg})$, diphenhydramine $(25 \mathrm{mg})$ and ranitidine $(50 \mathrm{mg}) 1 \mathrm{~h}$ prior to paclitaxel infusion to prevent hypersensitivity reaction. Patients received standard antiemetic treatment with a 5HT3 antagonist (before the administration of cytotoxic drugs and for 1 day after chemotherapy). All 35 patients received vitamin B6 (pyridoxine, $300 \mathrm{mg}$ ) orally once daily after lunch to prevent PPE.

Treatment was administered on an outpatient basis and was repeated if the absolute neutrophil count (ANC) was $>1,500 / \mathrm{mmc}$, platelet count $>100,000 / \mathrm{mmc}$ and non-hematologic toxicities were resolved. G-CSF was permitted when ANC was $<500 / \mathrm{mmc}$.

Toxicity assessment and definition. Toxicity was graded according to the National Cancer Institute Common Toxicity Criteria (NCI-CTC 3.0). Cardiac toxicity (defined as a decrease in LEVF $>10 \%$ from the baseline) was based on echocardiographic LEVF measurements that were performed at the
Table I. Patient characteristics.

\begin{tabular}{|c|c|c|}
\hline Enrolled patients & 35 & \\
\hline Evaluable for toxicity & 35 & $100 \%$ \\
\hline Evaluable for efficacy & 31 & $88.5 \%$ \\
\hline Age (years) & 60 (median) & 30-78 (range) \\
\hline$\geq 65$ & 19 & $54.2 \%$ \\
\hline \multicolumn{3}{|l|}{ Performance status (ECOG) } \\
\hline 0 & 29 & $82.8 \%$ \\
\hline 1 & 5 & $14.2 \%$ \\
\hline 2 & 1 & $2.8 \%$ \\
\hline \multicolumn{3}{|l|}{ Previous treatments } \\
\hline Surgery & 34 & $97.0 \%$ \\
\hline Adjuvant chemotherapy & 29 & $82.8 \%$ \\
\hline $\begin{array}{l}\text { Adjuvant anthracycline } \\
\text { chemotherapy }\end{array}$ & 18 & $51.4 \%$ \\
\hline $\begin{array}{l}\text { Doxorubicin } \\
\left(\text { dose } \mathrm{mg} / \mathrm{m}^{2}\right)\end{array}$ & $\begin{array}{c}240 \\
\text { (median) }\end{array}$ & $\begin{array}{l}160-240 \\
\text { (range) }\end{array}$ \\
\hline $\begin{array}{l}\text { Epidoxorubicin } \\
\left(\text { dose } \mathrm{mg} / \mathrm{m}^{2}\right)\end{array}$ & $\begin{array}{c}600 \\
\text { (median) }\end{array}$ & $\begin{array}{l}400-600 \\
\text { (range) }\end{array}$ \\
\hline $\begin{array}{l}\text { Oestrogen and/or } \\
\text { progesterone receptor-positive }\end{array}$ & 26 & $74.2 \%$ \\
\hline HER 2-positive & 5 & $14.2 \%$ \\
\hline \multicolumn{3}{|l|}{ Sites of disease } \\
\hline Bone & 17 & $48.5 \%$ \\
\hline Lung & 13 & $37.1 \%$ \\
\hline Nodes & 12 & $34.2 \%$ \\
\hline Liver & 12 & $34.2 \%$ \\
\hline Skin/soft tissue & 7 & $20.0 \%$ \\
\hline Pleura & 2 & $5.7 \%$ \\
\hline Breast & 1 & $2.8 \%$ \\
\hline Ovary & 1 & $2.8 \%$ \\
\hline \multicolumn{3}{|l|}{ No. of sites of disease } \\
\hline$>2$ & 28 & $80.0 \%$ \\
\hline
\end{tabular}

ECOG, Eastern Cooperative Oncology Group.

baseline and every 12 weeks and on 12-lead electrocardiogram that was performed at the baseline and every 4 weeks. These measurements were performed only during the treatment.

Dose modification of PLD and paclitaxel were permitted for hematological toxicity, increases in total bilirubin, cardiac toxicity and other NCI-CTC grade 3-4 events.

Assessment of efficacy and definition. Efficacy was measured as the overall response rate (complete and partial response) and overall survival (OS).

Responses were classified according to World Health Organization criteria. Computed tomography scans of lesions were carried out within 4 weeks prior to treatment commencing and repeated every 3 cycles. Patients who discontinued the study were evaluated for survival. Patients were assessable for response if they had early disease progression or had received at least 3 cycles of treatment with at least one tumor assessment. OS was measured from the time treatment commenced until patients succumbed to any cause. Distribution of time-to-event was estimated by the Kaplan-Meier product limit methods. 
Table II. Toxicity. ${ }^{\mathrm{a}}$

\begin{tabular}{lcc}
\hline Type of toxicity & $\begin{array}{c}\text { Grade } 1-2(\%) \\
(\mathrm{n}=35)\end{array}$ & $\begin{array}{c}\text { Grade 3-4 }(\%) \\
(\mathrm{n}=35)\end{array}$ \\
\hline Non-hematologic & 14.2 & 8.5 \\
PPE & 8.5 & - \\
Diarrhea & 2.8 & 2.8 \\
Mucositis & 10.0 & - \\
Nausea/vomiting & 7.8 & - \\
Asthenia & - & 2.8 \\
AST/ALT & 82.7 & 2.8 \\
Hair loss & 17.1 & - \\
Neurotoxicity & & 12.5 \\
Hematologic & 14.7 & 2.8 \\
Leukopenia & 13.5 & - \\
Anemia & 2.8 & \\
Thrombocytopenia & & \\
\hline
\end{tabular}

aAccording to NCI-CTC-3.0. PPE, palmar-plantar erythrodysesthesia; ALT, alanine aminotransferase and AST, aspartate aminotransferase.

\section{Results}

Between June 2003 and November 2007, 35 female patients with MBC and a high risk of cardiotoxicity were enrolled in the study. The median age of the patients was 60 years (range $30-78$ ), but 19 out of the 35 patients were $>65$ years of age. ECOG performance status ranged from 0 to 2 (Table I). The majority of patients $(80 \%)$ had two or more sites of disease, with the most common one being the bone (48.5\%), lung (37.1\%) and liver (34.2\%). A large number of patients $(82.8 \%)$ were previously treated with adjuvant chemotherapy and 18 were treated with adjuvant anthracycline-based chemotherapy. The median dose of adjuvant doxorubicin or epidoxorubicin received was 240 or $600 \mathrm{mg} / \mathrm{m}^{2}$, respectively. No patients were pre-treated for advanced disease. All 35 patients were evaluable for toxicity, while 31 were evaluable for efficacy.

Toxicity. All 35 patients evaluable for safety received a total of 175 cycles. The median number of cycles was 4 (range 1-9). The median cumulative dose of PLD was $150 \mathrm{mg} / \mathrm{m}^{2}$ (range 30-270) and the median cumulative dose of paclitaxel was $1,400 \mathrm{mg} / \mathrm{m}^{2}$ (range $280-2,520$ ). No patients required a dose reduction of PLD or paclitaxel. Treatment was discontinued in one patient after 1 cycle for grade 3 liver toxicity,
Table IV. Survival (31 evaluable patients).

\begin{tabular}{lcc}
\hline & $\begin{array}{c}\text { Median duration } \\
\text { (months) }\end{array}$ & $\begin{array}{c}\text { Range } \\
\text { (months) }\end{array}$ \\
\hline Complete response & 24 & $5-47$ \\
Partial response & 21 & $9-64$ \\
Stable disease & 12 & $5-40$ \\
Progressive disease & 12 & $6-22$ \\
Overall survival & 18 & $5-64$ \\
\hline
\end{tabular}

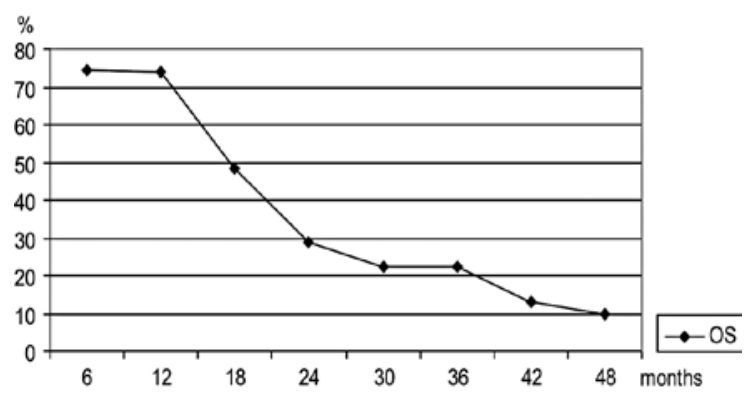

Figure 1. Overall survival for 31 evaluable patients (Kaplan-Meier method).

possibly related to the study treatment. No treatment interruptions or discontinuations for cardiac toxicity occurred, and no treatment-related deaths were reported. The toxicities are listed in Table II. Leukopenia (12.5\%) was the most frequently reported grade 3-4 toxicity and grade 4 anemia was recorded in 1 patient $(2.8 \%)$. Among the non-hematological adverse events, 1 case $(2.8 \%)$ of grade 3 liver toxicity was reported, as well as 1 case $(2.8 \%)$ of grade 3 mucositis and 3 cases $(8.5 \%)$ of grade 3 PPE G3. Grade 3 hair loss occurred in only $2.8 \%$ of patients.

No abnormal electrocardiograms were documented during treatment. No decrease in LEVF $>10 \%$ from the baseline was observed.

Efficacy. A total of 4 complete (12.9\%; 95\% CI 11-24.6) and 16 partial responses (51.6\%; 95\% CI 34.1-69) were achieved in 31 evaluable patients for an overall response rate of $64.5 \%$ (95\% CI 47.7-81.3). The median duration of complete and partial response was 13 months (range 1-14) and 15 months (range 4-36), respectively. A total of 6 patients had stable disease $(19.3 \%$; 95\% CI 5-33) with a median duration of 7 months (range 6-18), and 5 patients had progressive disease $(16.1 \%$; $95 \%$ CI 4-29). The median OS for

Table III. Response (31 evaluable patients).

\begin{tabular}{|c|c|c|c|c|}
\hline & No. $(\%)$ & Median duration (months) & Range (months) & $95 \% \mathrm{CI}$ \\
\hline Complete response & $4(12.9)$ & 13 & $1-14$ & $11.0-24.6$ \\
\hline Partial response & $16(51.6)$ & 15 & $4-36$ & $34.1-69.0$ \\
\hline Stable disease & $6(19.3)$ & 7 & $6-18$ & $5.0-33.0$ \\
\hline Progressive disease & $5(16.1)$ & - & - & $4.0-29.0$ \\
\hline Overall response rate & $20(64.5)$ & - & - & $47.7-81.3$ \\
\hline
\end{tabular}


all 31 evaluable patients was 18 months (range 5-64) with a median OS of 24 months for patients with complete response (range 5-47 months) and median OS of 21 months for patients with partial response (range 9-64 months). Patients with stable or progressive disease had a median survival of 12 months (range 5-40) and 12 months (range 6-22), respectively. No relationship was noted between patients pre-treated or not with anthracycline-based chemotherapy. Response and survival are reported in Tables III and IV and in Fig. 1.

\section{Discussion}

Despite advances in the early detection and adjuvant treatment of early stage disease, breast cancer remains a significant health problem. The outlook for patients with MBC is generally poor, with only $10 \%$ expected to survive 10 years after the diagnosis. The management of patients with MBC continues to evolve, but there remains considerable room for improvement. In recent years, many new chemotherapeutic agents have improved the efficacy and tolerability of chemotherapy.

In this study, a weekly schedule of both paclitaxel and PLD was selected to improve efficacy and tolerability. Weekly administration of paclitaxel was evaluated in numerous studies, and improvement in efficacy and tolerability was demonstrated (?).

Perez et al reported their findings of PLD administered at less frequent intervals to improve tolerability (12).

Moreover, the limited data on the safety and efficacy of PLD in elderly women with MBC are thought-provoking. Results of a phase II trial in MBC patients 65 years of age or older were recently reported by the European Organisation for Research and Treatment of Cancer. Efficacy and safety were comparable to that reported in other phase II and III studies suggesting that PLD is a useful alternative in elderly patients with MBC (33).

Herein, we report the results of efficacy and tolerability in a phase II study with weekly administration of both paclitaxel and PLD as first-line treatment in women with MBC. The enrolled patients were considered to be high risk for cardiotoxicity due to their age (over 65 years) and/or previous treatment with adjuvant anthracycline-based chemotherapy, previous treatment with RT on the left chest wall and/or hypertension. In this setting of patients we reported an overall response rate of $64.5 \%$. The median duration of complete and partial response was 13 and 15 months, respectively. The median OS was 18 months. The results achieved in this study are similar to those reported in the literature, which range overall response between 31 and $75 \%$ in combination therapy trials.

Regarding the safety profile, the combination of drugs used in the present study appear to show a favorable profile with low incidence of grade 3-4 toxicities. It is hypothesized that the weekly administration of PLD and paclitaxel should reduce the incidence and severity of adverse events. Notably, in patients that were over 65 years of age (up to 78 years) and in those considered to be high risk for cardiotoxicity, we observed no cardiac toxicity, including LEVF declines over $10 \%$. The improved cardiac safety of PLD was confirmed by two larger scale studies. The first of these, conducted by Safra et al, was a retrospective review of patients with solid tumors who had received cumulative doses of PLD ranging from 500 to $1,500 \mathrm{mg} / \mathrm{m}^{2}$ without a significant decrease in LEVF (34). A second large scale study evaluated the progression-free survival and cardiac safety of patients receiving PLD or conventional doxorubicin as first-line therapy for MBC. Although progression-free survival was similar for the two treatment groups, the incidence of cardiac toxicity was significantly lower with PLD (35).

In conclusion, several clinical studies support the use of PLD in patients with MBC (10-12). Moreover, there is growing evidence supporting the use of PLD monotherapy or combination regimens as first-line treatment for women with MBC. In the population of women with $\mathrm{MBC}$ and with high risk for cardiotoxicity, weekly paclitaxel plus PLD regimen appears to be a well-tolerated and effective treatment modality.

\section{References}

1. Early Breast Cancer Trialist Group (EBCTCG): Effect of chemotherapy and hormonal therapy for early breast cancer on recurrence and 15-year survival: an overview of the randomized trials. Lancet 365: 1687-1717, 2005.

2. Hortobagyi GN: Anthracyclines in the treatment of cancer: an overview. Drugs 54 (Suppl 4): 1-7, 1997.

3. Von Hoff D, Layard M, Basa P, Davcis HL, von Hoff AL, Rozencweig M and Muggia FM: Risk factors for doxorubicininduced congestive heart failure. Ann Inter Med 91: 710-717, 1979.

4. Swain S, Whaley FS and Ewer MS: Congestive heart failure in patients treated with doxorubicin: a retrospective analysis of three trials. Cancer 97: 2869-2879, 2003.

5. Pai VB and Nahata MC: Cardiotoxicity of chemotherapeutic agents: incidence, treatment and prevention. Drug Saf 22: 263-302, 2000

6. Balmer C and Valley AW: Basic principles of cancer treatment and cancer chemotherapy. In: Pharmacotherapy: A Pathophysiology Approach. 3rd edition. Di Piro JT, Talbert RL, Yee GC, et al (eds). Appleton and Lange, Stanford, pp2403-2465, 1997.

7. Waterhouse DN, Tardi PG, Mayer Ld and Balli MB: A comparison of liposomal formulation of doxorubicin with drug administered in free form: changing toxicity profiles. Drug Saf 24: 903-920, 2001.

8. Maluf FC and Spriggs D: Anthracyclines in the treatment of gynecologic malignancies. Gynecol Oncol 85: 18-31, 2002.

9. Gabizon AA: Liposomal anthracyclines. Hematol Oncol Clin North Am 8: 431-450, 1994.

10. Rivera E: Liposomal anthracyclines in metastatic breast cancer: Clinical update. Oncologist 8 (Suppl 3): 3-9, 2003.

11. Androulakis N, Kouroussis C, Mavroudis D, Kakolyris S, Souglakos J, Agelaki S, Kalbakis K, Malas K, Pallis A, Samonis G and Georgoulias V: Phase I study of weekly paclitaxel and liposomal doxorubicin in patients with advanced solid tumours. Eur J Cancer 38: 1992-1997, 2002.

12. Perez AT, Domenech GH, Frankel C and Vogel CL: Pegylated liposomal doxorubicin (Doxil) for metastatic breast cancer: the Cancer Research Network, Inc. experience. Cancer Invest 20 (Suppl 2): 22-29, 2002.

13. Rivera E, Valero V, Arun B, Royce M, Adinin R, Hoelzer K, Walters R, Wade JL, Pusztai L and Hortobagyi GN: Phase II study of pegylated liposomal doxorubicin in combination with gemcitabine in patients with metastatic breast cancer. J Clin Oncol 21: 3249-3254, 2003.

14. Fabi A, Ferretti G, Papaldo P, Salesi N, Ciccaresi M, Lo russo V, Carlini P, Carpino A, Mottolese M, Cianciulli AM, Giannarelli D, Sperduti I, Felici A and Cognetti F: Pegylated liposomal doxorubicin in combination with gemcitabine: a phase II study in anthracyclines-naïve and anthracyclines pretreated metastatic breast cancer patients. Cancer Chemother Pharmacol 57: 615-623, 2006.

15. Gebbia V, Mauceri G, Fallica G, Borsellino N, Tirrito ML, Testa A, Varvara F, Colombo A and Ferrera P: Pegylated liposomal doxorubicin in combination with vinorelbine in metastatic breast carcinoma. Oncology 63: 23-30, 2002. 
16. Ardavanis A, Mavroudis D, Kalbakis K, Malamos N, Syrigos K, Vamvakas L, Kotsakis A, Kentepozidis N, Kouroussis C, Agelaki S and Geogoulias V: Pegylated liposomal doxorubicin with vinorelbine as salvage treatment in pretreated patients with advanced breast cancer: a multicentre phase phase II study. Cancer Chemother Pharmacol 58: 742-748, 2006.

17. Overmoyer B, Silverman P, Holder LW, Tripathy D and Henderson IC: Pegylated liposomal doxorubicin and cyclophophamide as first line therapy for patients with metastatic or recurrent breast cancer. Clin Cancer 6: 150-157, 2005.

18. Vandenberg TA, Trudeau M, Provencher L, Panasci LC, Yelle L, Rayson D, Latreille J, Clemons M, Giroux M and Pouliot J: Pegylated liposomal doxorubicin (PLD) with cyclophosphamide (c) as 1st-line chemotherapy for metatstatic breast cancer (MBC) patients previously treated with adjuvant anthracyclines. J Clin Oncol 24: 10627, 2006.

19. Rigatos SK, Tsavdaridis D, Athananasiadis A, Stathopoulos JG and Stathopoulos GP: Paclitaxel and liposomal doxorubicin (Caelyx) combination in advanced breast cancer patients: A phase II study. Oncol Rep 10: 1817-1819, 2003

20. Simoncini E, Ferrari VD, Amoroso V, Valcamonico F, Grisanti S, Vassalli L, Marpicati P, Montini E, Rangoni G and Marini G: Bi-weekly administration of pegylated liposomal doxorubicin plus paclitaxel in metastatic breast cancer (MBC) patients: a phase II study. J Clin Oncol 23: 844, 2005.

21. Vorobiof DA, Rapoport BL, Chasen MR, Slabber C, McMichael G, Eek R and Mohammed C: First line therapy with paclitaxel (Taxol) and pegylated liposomal doxorubicin (Caelyx) in patients with metastatic breast cancer: a multicentre phase II study. Breast 13: 219-226, 2004.

22. Rossi D, Baldelli AM, Casadei V, Fedeli SL, Alessandroni P, Catalano V, Giordani $P$, Ceccolini $M$, Graziano $F$ and Catalano G: Neoadjuvant chemotherapy with low dose of pegylated liposomal doxorubicin plus weekly paclitaxel in operable and locally advanced breast cancer. Anti-Cancer Drugs 19: 733-737, 2008.

23. Alexopoulos A, Karamouzis MV, Stavrinides H, Ardavanis A, Kandilis K, Stavrakakis J, Georganta C and Rigatos G: Phase II study of pegylated liposomal doxorubicin (Caelyx) and docetaxel as first line treatment in metastatic breast cancer. Ann Oncol 15 891-895, 2004.

24. Morabito A, Gattuso D, Stani SC, Fanelli M, Ferraù F, De Sio L, Castellana MA, Lorusso V, Priolo D, Vitale S, Mariani L and Gasperini G: Safety and activity of the combination of pegylated liposomal doxorubicin and weekly docetaxel in advanced breast cancer. Breast Cancer Res Treat 86: 249-257, 2004.

25. Sparano JA, Makhson AN, Semiglazov VF, et al: Pegylated liposomal doxorubicin plus docetaxel improves time to progression without additive cardiotoxicity compared with docetaxel monotherapy in patients with advanced breast cancer previously treated with neoadjuvant-adjuvant anthracycline therapy: results from randomized phase III study. J Clin Oncol 27: 4522-4529, 2009.
26. De la Fouchardiere, Largillier R, Goubely Y, Hardy-Bessard AC, Slama B, Cretin J, Orfeuvre H, Paraiso D, Bachelot $T$ and Pujade-Lauraine E: Docetaxel and pegylated liposomal doxorubicin combination as first-line therapy for metastatic breast cancer patients: results of the phase II GINECO trial CAPYTTOLE. Ann Oncol 20: 1959-1963, 2009.

27. Vogel CL: Salvage chemotherapy of breast cancer. Semin Oncol 21: 19-24, 1996

28. Holmes FA, Walters RS, Theriault RL, Buzdar AU, Frye DK, Hortobagyi GN, Forman AD, Newton LK and Raber MN: Phase II trial of Taxol, an active drug in the treatment of metastatic breast cancer. J Natl Cancer Inst 83: 1797-1805, 1991.

29. Seidman AD, Hudis C, Albanel J, Tong W, Tepler I, Currie V, Moynahan ME, Theodoulou M, Gollub M, Baselga $\mathrm{J}$ and Norton L: Dose-dense therapy with weekly-1-hour paclitaxel infusion in the treatment of metastatic breast cancer. J Clin Oncol 16: 3353-3361, 1998.

30. Perez EA, Irwin DH, Patel R, Vogel CL and Kirshner J: A large phase II trial of paclitaxel administered as a weekly one hour infusion in patients with metastatic breast cancer. Proc ASCO 18: $126,1999$.

31. Loffler TM: Is there a place for 'dose-dense' weekly schedules of the taxoids? Sem Oncol 25 (Suppl 12): 32-34, 1998

32. Verrill MW, Lee J, Cameron DA, Agrawal R, Cole Ferrigan E, and Yellowlees A: Anglo-Celtic IV: first results of a UK National Cancer Research Network randomized phase III pharmacogenetic trial of weekly compared to 3 weekly paclitaxel in patients with locally advanced or metastatic breast cancer (ABC). J Clin Oncol 25: LBA1005, 2007.

33. Coleman RE, Biganzoli L, Canney P, Dirix L, Mauriac L, Chollet P, Batter V, Ngalula-Kabanga E, Dittrich C and Piccart M: A randomised phase II study of two different schedules of pegylated liposomal doxorubicin in metastatic breast cancer (EORTC 10993). Eur J Cancer 42: 882-887, 2006.

34. Safra T, Muggia F, Jeffers S, Tsao-Wei DD, Groshen S, Lyass O Henderson R, Berry G and Gabizon A: Pegylated liposomal doxorubicin (Doxil): reduced clinical cardiotoxicity in patients reaching or exceeding cumulative doses of $500 \mathrm{mg} / \mathrm{m}^{2}$. Ann Oncol 11: 1029-1033, 2000.

35. O'Brien MER, Wigler N, Inbar M, Rosso R, Grischke $E$, Santoro A, Catane R, Kieback DG, Tomczak P, Ackland SP, Orlandi F, Mellars L, Alland L and Tendler C: Reduced cardiac toxicity and comparable efficacy in a phase III trial of pegylated liposomal doxorubicin HCL (Caelyx/Doxil) versus conventional doxorubicin for first-line treatment of metastatic breast cancer. Ann Oncol 15: 440-449, 2004. 